\section{Maintenance of Low Disease Activity following Tumor Necrosis Factor Inhibitor Dose Tapering in Ankylosing Spondylitis}

To the Editor:

Clinicians, patients, and others have shown considerable interest in the subject of tumor necrosis factor inhibitor (TNFi) dose tapering in ankylosing spondylitis (AS) because of the drug's high cost and potential for toxicity ${ }^{1,2,3}$. In the ANSWERS (ANkylosing Spondylitis With Etanercept RegimeS) trial, we demonstrated that over $50 \%$ of participants originally treated with etanercept (ETN) $50 \mathrm{mg}$ once weekly (OW) who were then randomized to a tapered dose of ETN $25 \mathrm{mg}$ OW maintained the primary outcome measure [Bath Ankylosing Spondylitis Disease Activity Index (BASDAI) reduction by $\geq 50 \%$ or $\geq 2$ points, and a $\geq 2$-unit reduction in spinal pain measured on a 10-point visual analog scale] at the 6-month followup ${ }^{4}$.

All patients enrolled in the initial study gave their written consent. Ethical approval for the ANSWERS study was granted by North West 2 REC Liverpool Central (UK); trial register: National Institute for Health Research National Research Register (public.ukcrn.org.uk/search, Study ID: 9375) and European Clinical Trial Database (eudract.ema.europe.eu/ eudract-web/index.faces, EudraCT number: 2010-029013-10). We have now followed this cohort prospectively to determine whether the "tapered" patients in the ETN $25 \mathrm{mg}$ OW arm could successfully maintain the primary outcome measure in longterm followup. In patients who failed to maintain this response, full-dose ETN $50 \mathrm{mg}$ OW was reinstated.

Twelve patients were included within the ETN $25 \mathrm{mg}$ OW group; 75\% men, mean age 52 years, median BASDAI 2.8 [interquartile range (IQR) 2.0]. After a mean followup period of 50 months, 4 patients (33\%) continued treatment with ETN $25 \mathrm{mg}$. One patient discontinued ETN because of side effects and has not been receiving biologic therapy. The remaining 7 patients experienced a flare of disease after a mean of 16 months and were reinstated with ETN $50 \mathrm{mg}$ OW; 5 reattained low disease activity and 2 were switched and responded to an alternative TNFi.

Twenty-one patients continued treatment with ETN $50 \mathrm{mg}$ : 95\% men, mean age 60 years, median BASDAI 1.9 (IQR 1.6). Fourteen patients (67\%) continued treatment with ETN $50 \mathrm{mg}, 3$ were lost to followup, 2 developed inflammatory bowel disease and switched to adalimumab (ADA), 1 flared at 15 months and switched to ADA, and another discontinued ETN because of mood disturbance and has not continued biologic therapy.
These data indicate that dose reduction is feasible in patients with stable AS and that disease control can be regained either by reverting to full-dose therapy or by switching to an alternative TNFi. Larger studies are needed to determine the clinical phenotype of patients most suitable for dose tapering.

LAUREN STEEL, MBBS, BSc, MRCP (London), Rheumatology Department, Norfolk and Norwich University UK National Health Service (NHS) Foundation Trust; KARL GAFFNEY, MB ChB, BAO (Hons), FEGEMS, FRCPI, FRCP, Rheumatology Department, Norfolk and Norwich University Hospital NHS Foundation Trust, Norwich, UK. Dr. Gaffney received research grants and speaker/consultancy fees from AbbVie, MSD, Pfizer, Cellgene, Novartis, and UCB. The study described here was done in affiliation with BRITSpA (British Society for Spondyloarthritis). Address correspondence to Dr. K. Gaffney, Rheumatology Department, Norfolk and Norwich University NHS Foundation Trust, Colney Lane, Norwich NR8 5HE, UK. E-mail: karl.gaffney@nnuh.nhs.uk

\section{REFERENCES}

1. Fong W, Holroyd C, Davidson B, Armstrong R, Harvey N, Dennison E, et al. The effectiveness of a real life dose reduction strategy for tumour necrosis factor inhibitors in ankylosing spondylitis and psoriatic arthritis. Rheumatology 2016;55:1837-42.

2. Závada J, Uher M, Sisol K, Forejtová Š, Jarošová K, Mann H, et al. A tailored approach to reduce dose of anti-TNF drugs may be equally effective, but substantially less costly than standard dosing in patients with ankylosing spondylitis over 1 year: a propensity score-matched cohort study. Ann Rheum Dis 2016;75:96-102.

3. Plasencia C, Kneepkens EL, Wolbink G, Krieckaert CL, Turk S, Navarro-Compán V, et al. Comparing tapering strategy to standard dosing regimen of tumor necrosis factor inhibitors in patients with spondyloarthritis in low disease activity. J Rheumatol 2015;42:1638-46.

4. Yates M, Hamilton LE, Elender F, Dean L, Doll H, MacGregor AJ, et al. Is etanercept $25 \mathrm{mg}$ once weekly as effective as $50 \mathrm{mg}$ at maintaining response in patients with ankylosing spondylitis? A randomized control trial. J Rheumatol 2015;42:1177-85.

J Rheumatol 2017;44:8; doi:10.3899/jrheum.170057 